\title{
Editorial
}

\section{Universal Health Care Ahoy!}

\author{
Rajeev Gupta \\ Editor, RUHS Journal of Health Sciences, Chair, Academic Research Development Unit, \\ Rajasthan University of Health Sciences, Jaipur, Rajasthan, India
}

The hullabaloo surrounding the universal health insurance for 100 million below-poverty-line households under the Ayushman Bharat Pradhan Mantri Jan Arogya Yojana (AB-PMJAY) has masked an important component of the scheme- creation of 150,000 Health and Wellness Centres (HWCs) in the country. ${ }^{1}$ These health centres are to be created across the country in both urban and rural areas and shall vary with population density. Once implemented, these centres would be primary care hub for the whole country and one centre shall cater to a population of 5000-15000 people (about 1000-3000 families). If properly equipped and adequately manned (general physicians, nurses and primary health care workers) these centres would be go-to places for common ailments which account for more than $80 \%$ of health care in both rural and urban areas. The concept of provision of promotive and preventive health care is excellent although there is a need to focus not only on prevention but also on treatment of acute and chronic diseases. ${ }^{2}$

Primary (universal) health care as a concept of care for India was initially floated by the Bhore Committee in mid 1940 's. ${ }^{3}$ Sir David Bhore in his landmark report proposed a decentralized system of care with primary health centre (PHC) as a hub with multiple spokes in form of health centres. This proposal entailed provision of physicians at the PHCs and nurses, assistant nurses and health care workers at the spokes. Multiple PHC's were to be connected to community health centres (CHC) where primary specialists were to be available and district hospitals as centres-of excellence for specialist care. In this schema of healthcare, the medical college hospitals (one for multiple districts) were to be developed as institutions devoted mainly to teaching and research with selected super-specialty services at each. This scheme was successfully implemented in the British National Health Service in UK and has been running there for the last 70 years. ${ }^{4}$ Most of the Indian states adopted this scheme in some form of other but massive shortage of funds for creation of proper infrastructure and shortage of welltrained man-power resulted in severe deficiencies. ${ }^{2}$ The health centres and PHCs did not have space, equipment or manpower to cater to the rapidly increasing population and burgeoning demands of the modern health care.

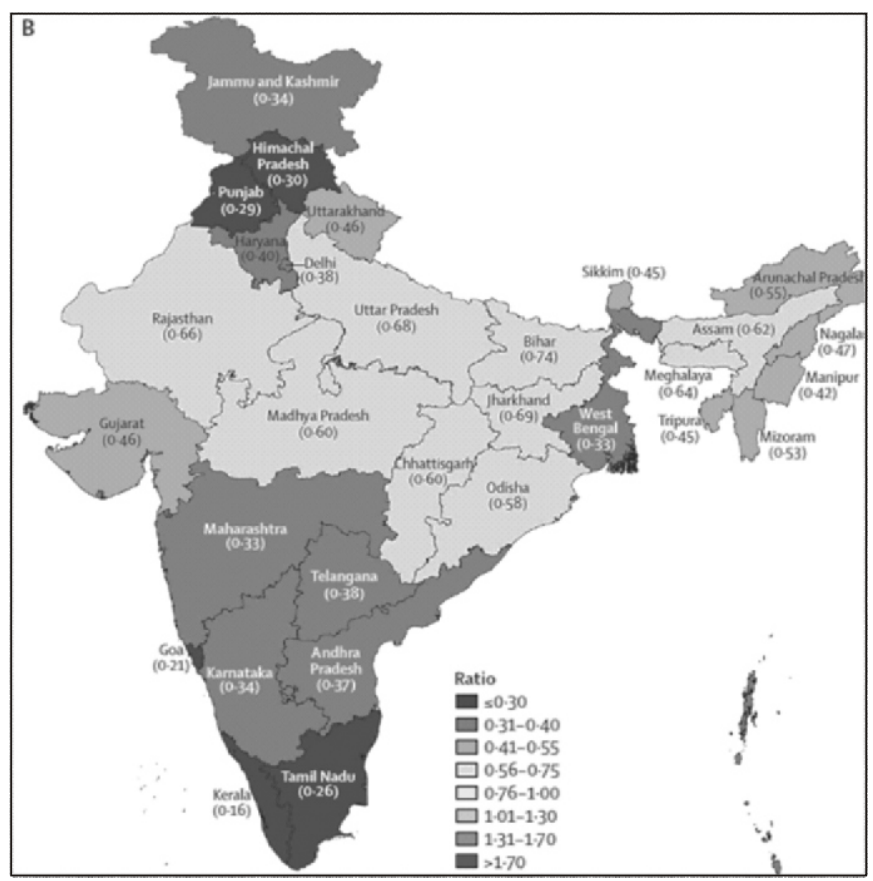

Figure 1: Epidemiological transition index (ratio) in different states of India for year 2016 according to

India State Level Disease Burden Initiative estimates.

Rapid epidemiological transition in India has been associated with control of diseases of poverty and pestilence and emerging epidemic of non-communicable diseases. ${ }^{5}$ This has further magnified the shortage of facilities and manpower. Indeed, in most of the states of the country the non-communicable diseases (cardiovascular diseases, diabetes, chronic respiratory diseases, mental health conditions, cancer, etc.) have replaced maternal and childhood diseases and infections as more 
important causes of deaths and disability. The India State Level Disease Burden Initiative study has reported that the epidemiological transition index (ETI) which is ratio of disease-burden from maternal, childhood and communicable diseases to non-communicable diseases and injuries is less than 1.0 in all the states of the country and is less than 0.5 in many states (Figure 1). ${ }^{6}$ This indicates that non-communicable diseases have surpassed other disease conditions and health services have to be planned accordingly.

Clearly, the HWC scheme under the PMJAY is still a work-in-progress and the central and state governments in India have to work hard to provide universal health coverage. The recent Astana Declaration by WHO has refocused global attention on universal health care. ${ }^{7}$ It has been restated as high-quality universal health care and it has been jointly declared by world leaders (including our Prime Minister) that "We will apply knowledge, including scientific as well as traditional, to strengthen primary health care, improve health outcomes, ensure access for all people to the right care at the right time, at the most appropriate level of care, while respecting their rights, needs, dignity and autonomy". This is only a slight modification from the concept of primary health care for all that was declared at Alma Ata in 1978 and is now known as the Almaty Declaration. ${ }^{8}$ India is a signatory to both these declarations.

If this dream of universal health care has to be developed, each HWC in India should not only have an adequate funding but also should be centres for-excellence in providing curative, promotive and preventive health care with 24-hour availability of general physicians, nurses, assistant nurses, and health workers at each centre. There should be adequate diagnostic and treatment facilities with round-the-clock availability of investigations, pharmaceuticals and other facilities. Proper manpower management and supply-chain intricacies are crucial to maintain excellence at such centres and there is a need for regular uninterrupted electricity and power supply. Basic infrastructure to promote social well being of health workers is also essential. ${ }^{9}$ All the demand-supply chain of health care at HWC should be guided by science and scientific research. ${ }^{2,10}$ It is crucial that efficient surveillance mechanisms are developed (using info-tech) to guide preventive, promotive and curative initiatives according to local disease epidemiology.

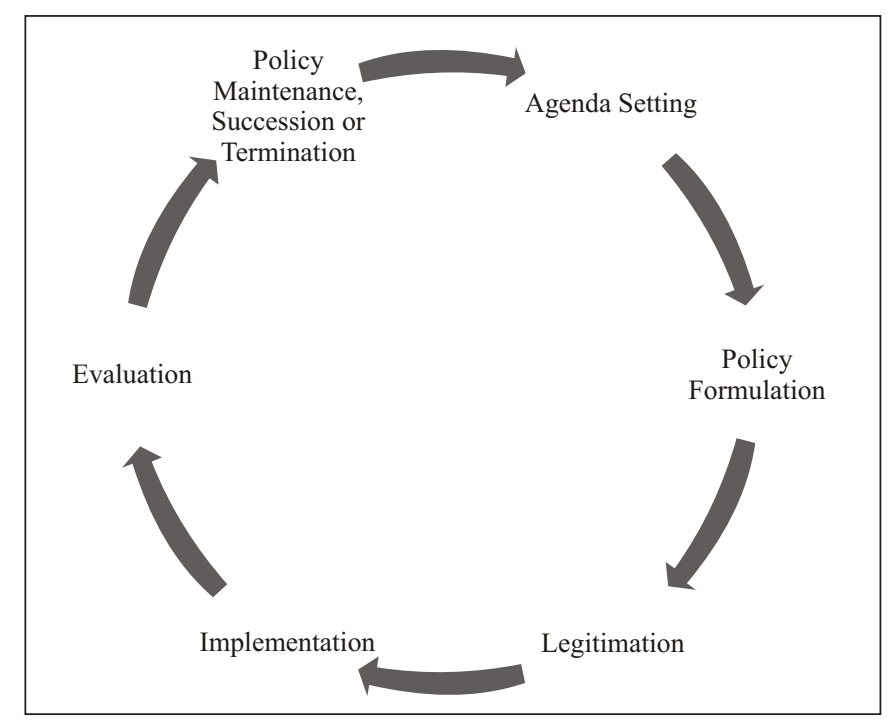

Figure 2: The policy cycle.

A policy implementation cycle exists in health care (Figure 2). ${ }^{11}$ The initiating phase of this cycle is political will and agenda setting. This followed by policy formulation, legitimation, implementation, evaluation and policy maintenance, succession or termination. For universal health care the Union Budget of year 2017 initially focused attention of polity on health care and ABPMJAY has compounded the focus. From idea to implementation is a difficult task but the political will to create such an infrastructure for good health is crucial. India needs to learn from experiences of large countries that have been successively providing publicly funded model of universal health care (UK, Nordic countries and China) and unlearn the US model of privatized and expensive health care. ${ }^{12,13}$ Successful implementation shall not only require the good-will of central government but shall need good-deeds of various state governments. Many states in India are working on different models of care and it shall be appropriate that audits of health systems and health care are performed with scientific rigor to guide policy. ${ }^{14}$ Only then the dream of high-quality universal health care for all of us in India shall be fulfilled.

\section{REFERENCES}

1. Ayushman Bharat-Pradhan Mantri Jan Aarogya Yojana (AB-PMJAY). Available at: http://pib.nic.in/newsite/ Print Release. aspx?relid=183624. Accessed 22 Dec 2018.

2. Prasad A, Lakhanpaul M, Narula S, Patel V, Piot P, Venkatapuram S. Accounting for the future of health in India. Lancet 2017; 389:680-82.

3. Duggal R. Bhore Committee (1946) and its relevance today. Indian J Pediatr 1991; 58:395-406. 
4. Appleby A, Abbasi K. The NHS at 70: loved, valued and affordable. BMJ 2018; 361:k1540.

5. Gupta R, Gupta KD. Coronary heart disease in low socioeconomic status subjects in India: An evolving epidemic. Indian Heart J. 2009; 61:358-67.

6. India State Level Disease Burden Initiative Collaborators. Nations within a nation: variations in epidemiological transition across the states of India, 1990-2016 in the Global Burden of Diseases Study. Lancet 2017; 390: 243760.

7. World Health Organization and UNICEF. Declaration of Astana. Available at: https://www.who.int/docs/defaultsource/primary-health/declaration/gcphc-declaration.pdf. Accessed 22 Dec 2018.

8. World Health Organization. Declaration of Alma-Ata. Almaty: World Health Organization, 1978.

9. Gupta R, Khedar RS, Gupta N, Chaudhary AK. Lack of physicians is not the root cause for poor rural healthcare in India. BMJ 2014; 348:g54. Response.
10. World Health Organization, World Bank. Monitoring progress towards universal health coverage at country and global levels: framework, measures and targets. Geneva, Switzerland, and Washington, DC: World Health Organization and the World Bank, 2014.

11. Cairney P. Policy concepts in 1000 words: the policy cycle and its stages. Available at: https://paulcairney.wordpress. com/2013/11/11/policy-concepts-in-1000-words-thepolicy-cycle-and-its-stages/.Accessed: 22 December 2018.

12. Reich MR, Harris J, Ikegami N, Maeda A, Cashin C, Arauja EC, et al. Moving towards universal health coverage: lessons from 11 country studies. Lancet 2016; 387:811-16.

13. Lancet Global Health. Financing for health: where there's a will ....... Lancet Glob Health. 2016; 4:e663.

14. Wadhera RK, Bhatt DL. Toward precision policy- the case of cardiovascular care. N Engl J Med 2018; 379:2193-95. 